\title{
PROFESSOR NÃO É POLÍCIA DO CONTROL C!INVESTIGANDO O PLÁGIO NA MEDIAÇÃO PEDAGÓGICA EM EAD.
}

\author{
SANTOS/SP JULHO/2018
}

\author{
Silvana Leodoro - UNIMES - silvanaleodoro@gmail.com \\ Elisabeth dos Santos Tavares - UNIMES - elisabeth.tavares@unimes.br
}

Tipo: Investigação Científica (IC)

Natureza: Descrição de Projeto em Andamento

Categoria: Métodos e Tecnologias

Setor Educacional: EDUCAÇÃO SUPERIOR

\begin{abstract}
RESUMO
O plágio é um fenômeno que, embora não seja recente, tem aumentando exponencialmente no ambiente escolar e acadêmico, seja em função da ampliação das fontes de informação disponíveis, seja pelos novos recursos de produção textual, seja pela lógica do hipertexto, ou - simplesmente porque nossa percepção sobre ele está aumentada, em função de certos recursos que nos permitem identifica-lo. E tal fenômeno tem gerado um enorme desconforto entre professores, para dizer o mínimo.

Dada sua recorrência, abrangência e generalidade, temos investigado o plagio (ou plagiarismo) enquanto um fenômeno complexo que transcende a noção de plágio versus autoria ou a "a sanha" de identificar e punir os plagiadores.

Através de algumas experimentações, observação participante e pesquisa bibliográfica damos andamento a uma investigação que objetiva pensar o plágio sob uma perspectiva didática $e$ metodológica e refutando as relações de saber e poder que imputam ao professor o papel de polícia do control $C$ e, ao mesmo tempo, reforçam uma cultura de trincheiras nas quais se opõem alunos $e$ professores.
\end{abstract}

Palavras-chave: Plágio. Mediação pedagógica. Aluno-Aprendente. Autoria.

\section{AGRADECIMENTOS}

GOSTARÍAMOS DE AGRADECER AO PROFESSOR LEANDRO SIQUEIRA POR SEU APOIO, IDEIAS E PARCERIA NESSA PESQUISA. 


\section{Introdução}

Atuamos em uma instituição tradicional na cidade de Santos que, há mais de uma década, oferece diversas licenciaturas na modalidade à distância. São treze cursos de licenciatura que atendem cerca de vinte mil alunos de diversos estados brasileiros, muitos dos quais buscando uma segunda titulação para ampliar suas possibilidades de trabalho. Nosso corpo docente é formado por cerca de cento e cinquenta professores dos quais $97 \%$ com formação stricto sensu, doutores e mestres e cerca de noventa tutores atuando na área específica de sua formação em nível superior e com pósgraduação lato sensu, além de vários outros profissionais nas áreas de apoio acadêmico, monitoria, ambiente virtual, apoio aos polos, tecnologia, entre outras. São números expressivos de uma estrutura que, ao longo desses anos, atravessou diversos marcos regulatórios, procedimentos de validação e avaliação e, claro, forte concorrência de mercado.

Dado o expressivo crescimento do contingente de alunos nessa modalidade de ensino, da ordem de 1120\% entre 2005 e 2015, segundo dados do Instituto Nacional de Pesquisas Educacionais Anísio Teixeira - INEP (CENSO DA EDUCAÇÃO SUPERIOR, 2015) os desafios não se concentram mais apenas na tarefa de legitimar a modalidade e lidar com o preconceito, mas aprimorar e aperfeiçoar processos, discutir a mediação pedagógica, conhecer melhor o alunado e, claro, manter-se no mercado.

No âmbito da mediação pedagógica, tem sido recorrente presenciar o desconforto de professores e tutores em relação à ocorrência de plagio entre os alunos, ou dito de outra forma, da prática de copiar (utilizando-se das teclas $\mathrm{Ctrl}+\mathrm{C}$ ) e colar (teclas $\mathrm{Ctrl}+\mathrm{V}$ ) frases, parágrafos ou textos inteiros de outras fontes sem indicar as devidas referências. Tal desconforto é expresso em um misto de revolta ou de resignação que se transborda em um desejo de punição ou em um sentimento de impotência. Por diversas vezes, indagamos esses professores sobre suas percepções em relação ao plágio e, quase unanimemente, a responsabilidade (culpa) é imputada ao aluno que, deliberada e intencionalmente, tentaria enganar aquele que avalia sua atividade. Os possíveis motivos apontados? Preguiça, descaso, falta de tempo, pressa, procrastinação, falta de entendimento ou interesse pela atividade, esperteza, desonestidade. A frequência em que isso ocorreria? Em todas as atividades que envolvam a escrita. A abrangência? A maioria dos alunos.

Essa percepção também é recorrente em reuniões nas quais se discute o fenômeno com a pretensão de alinhar orientações aos alunos e a necessidade de "vigiar e punir" os transgressores. Não raro, também somos atingidos pelo sentimento de impotência 
quando, a despeito dos nossos esforços, somos derrotados na tarefa de identificar o plágio e "enquadrar" o aluno. Todo esse ethos policialesco acaba por dominar nosso imaginário no momento da avaliação de textos e atividades: se está bom demais, é suspeito! E partimos em busca de provas do provável "delito".

Mas, se a frequência é tão alta e a abrangência tão generalizada, não estaríamos às voltas com um novo modus operandi na produção acadêmica de nossos alunos? Ou, quem sabe, o que teria mudado seria o nosso sensorium em relação a essa prática uma vez que, informatizados, também dispomos de meios de verificação dessa produção discente? Ou, infelizmente, trata-se da deterioração inexorável das práticas que, antes, supostamente, se pautavam por uma escrita autoral e agora são pautadas pela mera reprodução de conteúdo? Eis o que nos propomos investigar.

\section{Objetivos}

Nosso objeto de estudo é o plágio compreendido como um fenômeno complexo para o qual concorrem diversas causas de caráter tecnológico, histórico, pedagógico, até geracional, e que tem provocado substantivo mal-estar entre aqueles que avaliam atividades escolares e acadêmicas. Embora não esteja circunscrito à $\mathrm{EaD}$, como nessa modalidade a troca de textos ocorre sempre por meio digital, tanto as formas de produzilo quanto as de detecta-lo são ampliadas.

Nossos objetivos de pesquisa podem ser definidos como investigar o fenômeno do plágio, com ênfase primeira em sua ocorrência na educação à distância, como um fenômeno complexo e que possui conexões com as práticas de leitura, na relação com a autoria, nas transformações ocorridas dos meios e suportes de comunicação e produção de conteúdo, nas relações acadêmicas marcadas pelo impacto da concorrência de mercado e pela produtividade científica, sem deixar de mencionar sua implicação com as transformações mais gerais das sociedades contemporâneas resultantes do avanço das tecnologias de informação e de comunicação, da expansão do neoliberalismo e da própria reconfiguração das relações de poder, tema que, apesar de sua relevância, não trabalharemos neste momento por questões de foco. Neste trabalho, buscamos também refletir sobre o papel da docência em relação ao plágio no que tange aos processos pedagógicos e metodológicos e quanto à possibilidade de promoção de "educação para as fontes".

\section{Referencial teórico}

Krokoscz (2104) define preliminarmente o plágio como um estatuto "moral e 
coletivamente reprovado por representar uma fraude de autoria" (p. 12) e que no meio acadêmico assume nuances particularizadas uma vez que o leitor da obra, normalmente um professor, também é prejudicado.

Popularmente conhecido como apropriação indevida de obra ou conteúdo alheio que é apresentado como sendo próprio, o plágio está relacionado diretamente ao cotidiano acadêmico caracterizado como prática desonesta, incompatível com o escopo universitário de criação e desenvolvimento do conhecimento, o que requer reflexão e posicionamento institucional. (2014, p. 12)

Embora haja legislação que trate o plágio como "roubo de autoria" (KROKOSCZ, 2014, p. 24) e que esteja presente na Constituição Federal de 1988, na Lei Brasileira de Direitos Autorais (Lei 9610/98), e com punição prevista pelo Código Penal, no âmbito acadêmico é muito difícil tipificar a ocorrência criminosa por vários motivos: a legislação existe para resguardar o interesse do autor (pessoa física ou jurídica) no que se refere ao direito sobre sua obra e sobre os dividendos financeiros que dela, eventualmente, venham ocorrer. Sendo assim, cabe ao autor - que se sentir prejudicado - recorrer à justiça na defesa de seus interesses e fazendo uso de recursos que garantem a proteção patrimonial daquela obra (lei de patentes, direitos autorais etc). A lei garante ao autor o direito de paternidade sobre sua obra e, inversamente, dota-o do direito de cessão, empréstimo, venda e doação a terceiros.

Ora, um aluno que copia trechos de sites cujo conteúdo foi inserido por outros alunos, ou mesmo por professores, ou que recorre à compra de trabalhos feitos ou, ainda, que copia o trabalho de um colega, dificilmente terá o autor desses textos reclamando a sua autoria. Desse modo, o professor que se sente enganado pelo aluno não pode, legalmente, reclamar a autoria daquele texto ou trabalho tampouco afirmar o caráter criminoso da prática. Some-se a isso o fato de, muitas vezes, o conteúdo apresentado pelo aluno ser na verdade uma compilação de trechos de várias fontes ou de fragmentos de uma mesma fonte obrigando o professor a uma verdadeira arqueologia do texto para identificar o plágio.

Outra questão tratada pelo autor, diz respeito à ausência de uma tradição científica no universo escolar brasileiro e, consequentemente, do desconhecimento técnico por parte dos alunos, até mesmo pós-graduandos, em lidar com os rituais que envolvem os procedimentos e técnicas de pesquisa. Mesmo quando dominam as técnicas de pesquisa, os estudantes não parecem ter clara a relação entre o seu não cumprimento e o ato de plagiar, talvez porque não tenham consciência (ou percepção) plena de seu próprio papel de pesquisador em um contexto científico mais amplo. "Não obstante, a condição de escrita do estudante brasileiro caracteriza-se muito mais como um hábito desvirtuado de composição textual, marcado mais pela reprodução do que pela criação" 
(Idem, p. 33).

Seria essa não-percepção de ser pesquisador reflexo de uma tradição escolar que não privilegia a pesquisa e que adota a cópia, a transcrição como recurso que, embora importante nas séries iniciais, transcorre durante toda a vida escolar do alunado? Sobre a natureza do plágio, Krokoscz ainda afirma existirem diferentes tipos e formatos, inclusive, no que se refere à sua intencionalidade ou acidentalidade, pontuando que nem todo plágio ocorreria como uma "trapaça". A tipologia dos plágios foi feita a partir da observação de como as principais universidades americanas vem classificando-o e das ações desenvolvidas a partir dessa tipologia. No Brasil, embora existam alguns esforços iniciais nesse sentido, ainda não existe uma convenção sobre esses tipos de plágios adotada pelas instituições de ensino.

Se o plágio é entendido em oposição à autoria, é preciso destacar que esta noção vive uma crise provocada, principalmente, pelas novas tecnologias que tiveram "influência significativa no processo de escrita" (Ibidem, p. 73) e estabeleceram um novo modus operandi de refação, reorganização e arquivamento de textos, além de terem ampliado o acesso ao conhecimento compreendido agora, mais do que antes, como um patrimônio comum.

Krokoscz defende que a discussão sobre a ocorrência do plágio no meio acadêmico deve ir muito além culpabilização do aluno e que é preciso ampliar o foco para a própria tradição reprodutivista de ensino e da consequente falta de familiaridade e reflexão pelo aluno, principalmente - sobre a autoria, além de uma frágil tradição do fazer pesquisa durante todos os ciclos da educação básica. É preciso considerar as contemporâneas transformações ocorridas tanto na forma, quanto na velocidade e na abrangência com a qual temos acesso às informações - e a um conhecimento cada vez com status de patrimônio comum - e também aos vários dispositivos e recursos de produção de novos conteúdos que, efetivamente, com a rede mundial de computadores, foram pulverizados. Além disso, alunos e pesquisadores estão envolvidos em uma intensa lógica de produção científica e acadêmica e que o "produtivismo científico" seria um componente que favorece, inclusive, um ambiente institucional de tolerância, senão de permissividade, em relação aos mais variados tipos de plágio.

Portanto, o plágio acadêmico é um problema que precisa ser analisado desde uma perspectiva histórica e global, na qual sejam considerados os aspectos que o caracterizam desde sua gênese até a atualidade e também reconhecidos os esforços já realizados e resultados alcançados mundialmente em seu enfrentamento. (Ibidem, $p$. 50)

Somada a todas essas proposições, sugerimos adicionar a noção de que o aluno, 
mesmo no ensino superior, ainda possui uma condição de aprendente, de pesquisador-em-formação e que as instituições devem estimular a formação desse ethos pesquisador. Mas, para isso, além de ações de orientação, é preciso ter clareza sobre a percepção do que venha a ser o plágio pelo próprio corpo docente e, conjuntamente, pesquisar os processos de escrita e aprendizagem dos alunos mediados por esses contemporâneos dispositivos de informação. A figura a seguir sintetiza essas proposições:

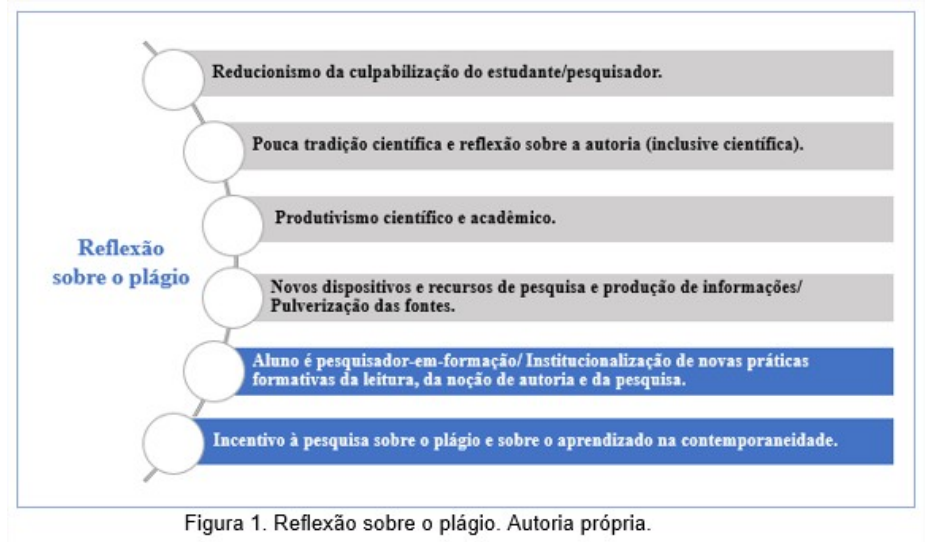

\section{Procedimentos metodológicos}

Sob uma perspectiva foucaultiana que não propõe exatamente uma metodologia, mas um conjunto de teorizações acerca de acontecimentos histórica e socialmente datados, não existe teoria dissociada da prática porque toda teorização nasce sob determinadas circunstâncias e escolhas, portanto, se não é possível pensar em neutralidade da pesquisa ou do sujeito do conhecimento tampouco se pode afirmar que a metodologia circunscreva-se apenas a ritos e técnicas assépticas quando ela própria é uma escolha que depende do compromisso do investigador para com suas práticas. Portanto, sob essa ótica, não há um desenho pronto e acabado do percurso, mas a predisposição em amadurecê-lo ao longo de sua trajetória. Isto posto, elencamos as etapas previstas nessa pesquisa e, até o momento da elaboração desse relato, estivemos envolvidos com as etapas (1), (2) e (3). São elas: (1) pesquisa bibliográfica sobre o plágio e a autoria; (2) observação participante (3) ações experimentais realizadas em atividades com os alunos. As demais etapas serão desenvolvidas futuramente, são elas: (4) entrevistas com professores sobre as representações que fazem do plágio e (5) pesquisas com alunos e egressos.

\section{Apresentação e discussão dos resultados}

A etapa (1) de pesquisa bibliográfica consistiu na busca por pesquisas e teses sobre 
plágio partindo da biblioteca digital da Universidade de São Paulo e sobre autores que tratam das noções de autoria e da leitura. Essa etapa subsidiou a abordagem teórica desse artigo. Na etapa (2), de observação participante junto ao corpo docente, verificamos que embora aos professores seja imputada a responsabilidade de fiscalizar e punir a prática no plágio, na prática observa-se que:

- As instituições de ensino brasileiras, em sua grande maioria, não disponibilizam aos professores e alunos ferramentas automatizadas de detecção de plágio, os chamados softwares antiplágio.

- Alguns softwares antiplágio disponibilizam gratuitamente a checagem de um número limitado de palavras ou caracteres e oferecem a opção paga para a varredura de textos maiores ou arquivos. Em nossas observações, a maioria dos professores consultados, mesmo os que orientam Trabalhos de Conclusão de Curso (TCC), não é usuária desse tipo de software na modalidade paga.

- A varredura realizada pelos softwares de antiplágio, normalmente, leva mais tempo quanto maior for o refinamento dos critérios de busca e altera o tempo que o professor dedica a correção de suas atividades e, talvez, por esse motivo, muitos prefiram consultar sites de busca.

- Normalmente, os professores - ao "desconfiarem" de plágio - verificam o texto do aluno copiando partes desse texto colando-as em um site de buscas, normalmente o Google.com, a fim de encontrar a fonte original da informação. Não dispomos de dados estatísticos sobre a eficácia desse procedimento, mas em nossa experiência já ocorreu de uma busca que não retornou com resultados em determinado site ter tido outras respostas em outro site.

- O resultado de uma varredura feita por um software antiplágio requer uma interpretação dos dados obtidos, uma vez que ele pode indicar reproduções que foram devidamente referenciadas ao final do texto, uma vez que ele se baseia na coincidência de dados. Portanto, mesmo com essa ferramenta, mais complexa sobre o ponto de vista de sua finalidade, os resultados obtidos precisam de interpretação.

- Quando indagados sobre o que consideram plágio e suas múltiplas formas e gradações, os professores parecem ter em comum a noção de sua ocorrência, mas não uma clareza conceitual ou conformidade ao defini-lo. Essa percepção sobre o plagio parece-nos, também, um elemento importante a ser pesquisado porque diz respeito às representações que são feitas sobre esse fenômeno.

Essas observações nos permitiram inferir que em cada atividade proposta sempre haverá um conjunto de alunos que mesmo tendo apresentado conteúdo reproduzido de alguma fonte não indicada terá sua atividade avaliada normalmente (à despeito de ter 
cometido plágio), enquanto outro conjunto de alunos - com atividades com as mesmas características - terá sua nota reduzida ou zerada conforme a sensibilidade e o critério de avaliação adotado pelo professor.

A etapa (3), de experimentações, envolveu nossos alunos da Licenciatura em Ciências Sociais ao longo de três semestres letivos. Para este relato de pesquisa, selecionamos os resultados obtidos em uma atividade dissertativa (ATD1) ocorrida no início de cada semestre em uma disciplina (componente curricular) denominada Teoria Política Clássica ofertada no $2^{\circ}$. semestre da licenciatura, composta de 6 semestres. Ainda que as experimentações tenham ocorrido também em outras atividades, de outras disciplinas, em diferentes etapas do processo formativo dos licenciandos, os resultados obtidos nessa etapa inicial do curso demostraram o potencial educativo das ações experimentais que denominamos educação para as fontes. A educação para as fontes consiste em planejar atividades acadêmicas que contemplem, além dos objetivos educacionais explicitados, questões que fomentem a leitura das fontes indicadas e a escrita autoral dos alunos, além de sinalizar pormenorizadamente os passos necessários à realização da atividade e à indicação das fontes consultadas por ele. Essas ações visam mitigar a ocorrência de plágio nas atividades acadêmicas e, também, fomentar a leitura e a escrita autoral dos alunos.

Partindo, portanto, do objeto de estudo plágio, a variável considerada foi a inserção das fontes consultas pelo aluno na ATD1, verificando se essa indicação ocorreu no modelo ABNT (como referências) ou de modo incompleto citando, por exemplo, apenas a URL do endereço pesquisado ou o nome de um livro. Os resultados obtidos são representados no Gráfico 1 que apresenta cronologicamente os percentuais de indicação das fontes no formato ABNT (barra azul), de modo incompleto (barra laranja) e ausentes de indicação das fontes (barra cinza) nos dois semestres letivos de 2017 e primeiro semestre letivo de 2018, conforme segue:

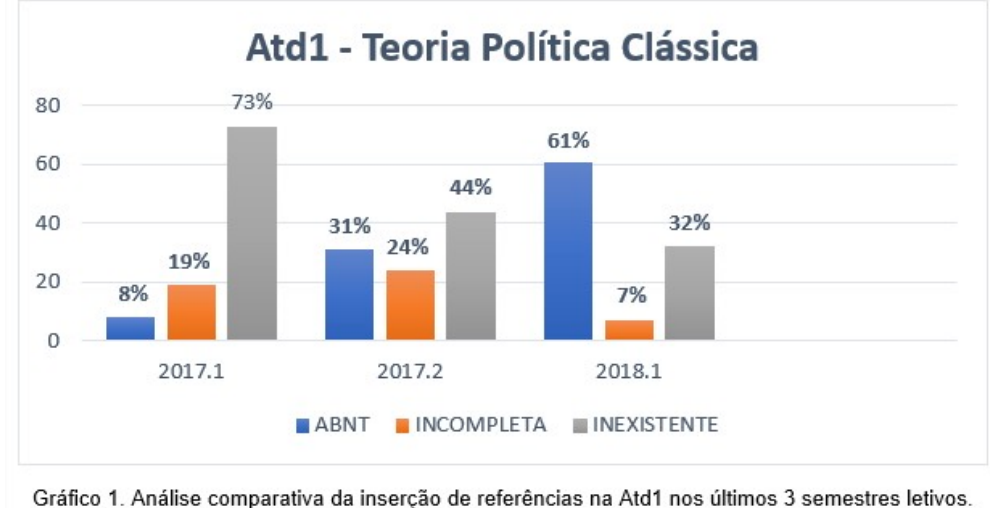

Conforme podemos observar no gráfico 1 , do total de alunos que realizou a ATD1 em 
cada semestre, o percentual de alunos que inseriu as fontes consultadas no modelo ABNT aumentou de $8 \%$ em 2017.1 para $61 \%$ em 2018.1, enquanto que o percentual de alunos que não indicou quaisquer fontes consultadas diminuiu de $\mathbf{7 3 \%}$ em 2017.1 para 32\% em 2018.1. Portanto, houve um expressivo aumento da indicação das fontes consultadas pelos alunos e tal aumento se deveu, em nosso entendimento, às ações de educação para as fontes. Ao considerarmos também os valores percentuais de indicação incompleta das fontes (19\%, 24\% e 7\% respectivamente em 2017.1, 2017.2 e 2018.1) observamos que ocorreu, durante o experimento, praticamente uma inversão no percentual referente a ausência de indicação de fontes, 73\% em 2017.1, para o percentual de alunos que fizeram algum tipo de indicação: $68 \%$ em 2018.1 , seja ela no formato ABNT ou incompleto. Uma inversão bastante positiva ao nosso ver. Reproduzimos a seguir, as atividades em questão propostas nesses três semestres:

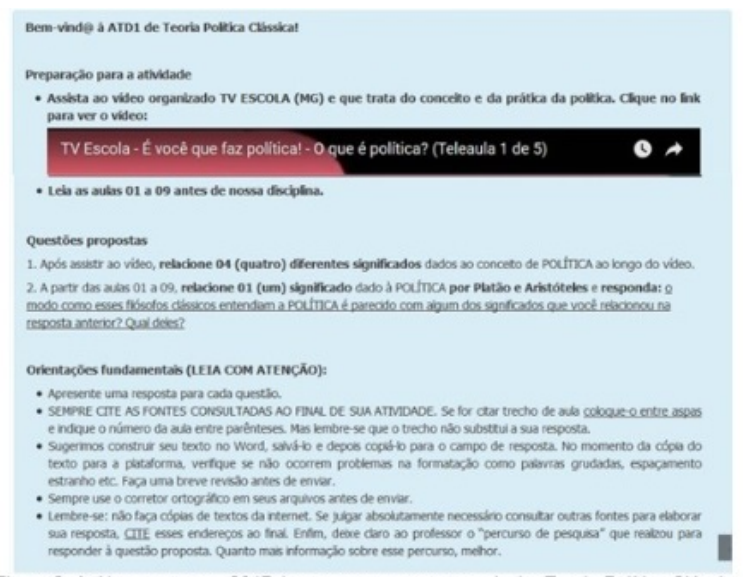

Figura 2. Atd1 proposta em 2017.1 para o componente curricular Teoria Politica Clássica.

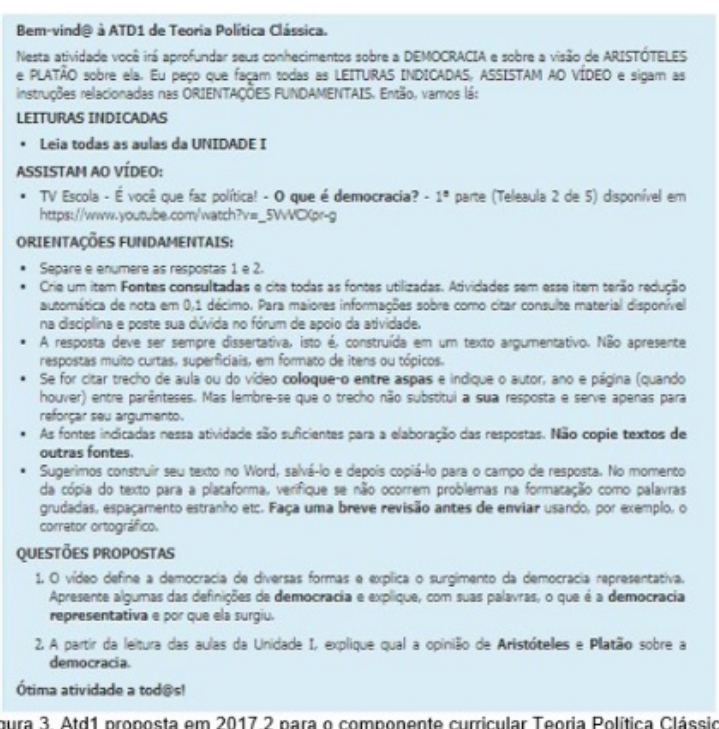

Figura 3. Atd1 proposta em 2017.2 para o componente curricular Teoria Politica Clássica
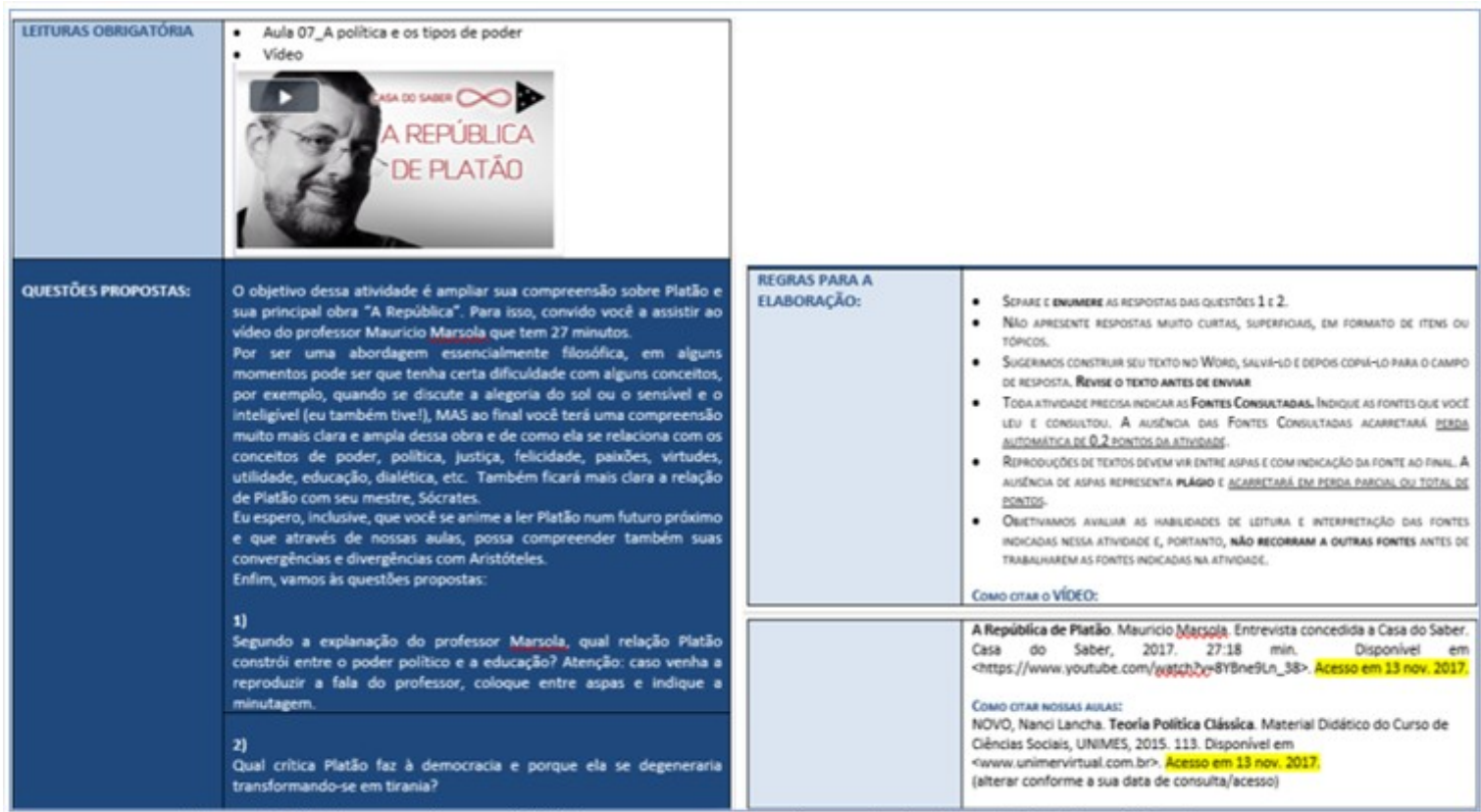

Figura 4. Atd1 proposta em 2018.1 para o componente curricular Teoria Política Clássica. 
Note-se que o detalhamento dos procedimentos para realização das atividades e indicação das fontes foi sendo ampliado a cada semestre chegando, inclusive, a indicar o formato modelo ABNT das fontes indicadas nas atividades.

\section{Considerações finais}

A relação entre o professor e seus alunos deve ser pautada pela intenção pedagógica, pelo acolhimento, pela interação e não se prestar a uma conduta policialesca. Sabemos que a ocorrência de plágio é um problema com alcance mundial em todas as modalidades de ensino, e, por isso mesmo, reforçamos a importância de enfrenta-lo didática e metodologicamente. Mas esse enfrentamento deve ocorrer tanto de forma institucional, com regras e prodecimentos claros para toda a comunidade escolar, quanto pela postura dos próprios professores ao elaborarem e avaliarem suas atividades compreendendo que alunos da graduação ainda necessitam de orientação sobre leitura, escrita e referenciação bibliográfica. Enfim, precisamos desmontar as trincheiras e discutir as práticas acadêmicas de ambos os lados. Em nosso caso, criamos no início de 2018 um fórum permanente de discussão sobre plágio, com instruções em texto e imagem, em todas as salas. Experiência essa que pretendemos abordar de forma mais detalhada em um futuro trabalho.

\section{Referências}

CENSO NACIONAL NA EDUCAÇÃO SUPERIOR. Instituto Nacional de Pesquisas Educacionais Anísio Teixeira. INEP, 2015. Disponível em: Acesso em 14.mar.2018.

FOUCAULT, Michel. A ordem do discurso. São Paulo: Edições Loyola, 2014.

FREIRE, Paulo. Pedagogia da autonomia: saberes necessários à prática educativa. Rio de Janeiro: Paz e Terra, 1996.

KROKOSCZ, Marcelo. Outras palavras: análise dos conceitos de autoria e plágio na produção textual científica no contexto pós-moderno. 2014. 160 f. Tese (Doutorado em Ensino de Ciências e Matemática) - Faculdade de Educação, Universidade de São Paulo, São Paulo.

SILVA, Marco Antonio. Sala de aula interativa. Rio de Janeiro: Quartet, 2007. 